\title{
World must prepare for inevitable flu pandemic, says WHO
}

\author{
Cite as: CMAJ 2019 April 8;191:E405. doi: 10.1503/cmaj.109-5735
}

Posted on cmajnews.com on Mar. 20, 2019.

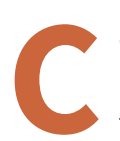
ountries must prepare for the next global influenza pandemic, the World Health Organization (WHO) warns. There is a real and ongoing risk that a new flu virus will jump from animals to human, according to WHO Director-General Dr. Tedros Adhanom Ghebreyesus.

"The question is not if we will have another pandemic, but when," the directorgeneral stated. As things stand, "we are still not prepared enough."

Influenza remains one of the world's greatest public health challenges, with up to five million severe cases each year and about three major pandemics per century. As many as 400000 people died during the H1N1 pandemic in 2009, and the virus infected at least one in five people worldwide within a year of the outbreak.

WHO is calling on countries to step up preparations for the next pandemic as part of a new global influenza strategy as "the cost of a major influenza outbreak will far outweigh the price of prevention."

Vaccination is the most effective way to prevent the spread of the virus and is especially important for health workers and people at high risk of complications, WHO says.

Countries must also build their capacities for disease surveillance, prevention and control, and develop better tools, including more effective vaccines and treatments. To achieve this, WHO recommends that all countries have a tailored influenza program that contributes to global preparedness.

According to WHO, these preparations will also equip countries to better identify other infectious diseases like Ebola and Middle East respiratory syndrome-related coronavirus.
The 2009 H1N1 pandemic exposed gaps in Canada's influenza response. In addition to logistical problems distributing the vaccine, a Senate review found issues with communication, cooperation between governments, and health infrastructure in Indigenous communities.

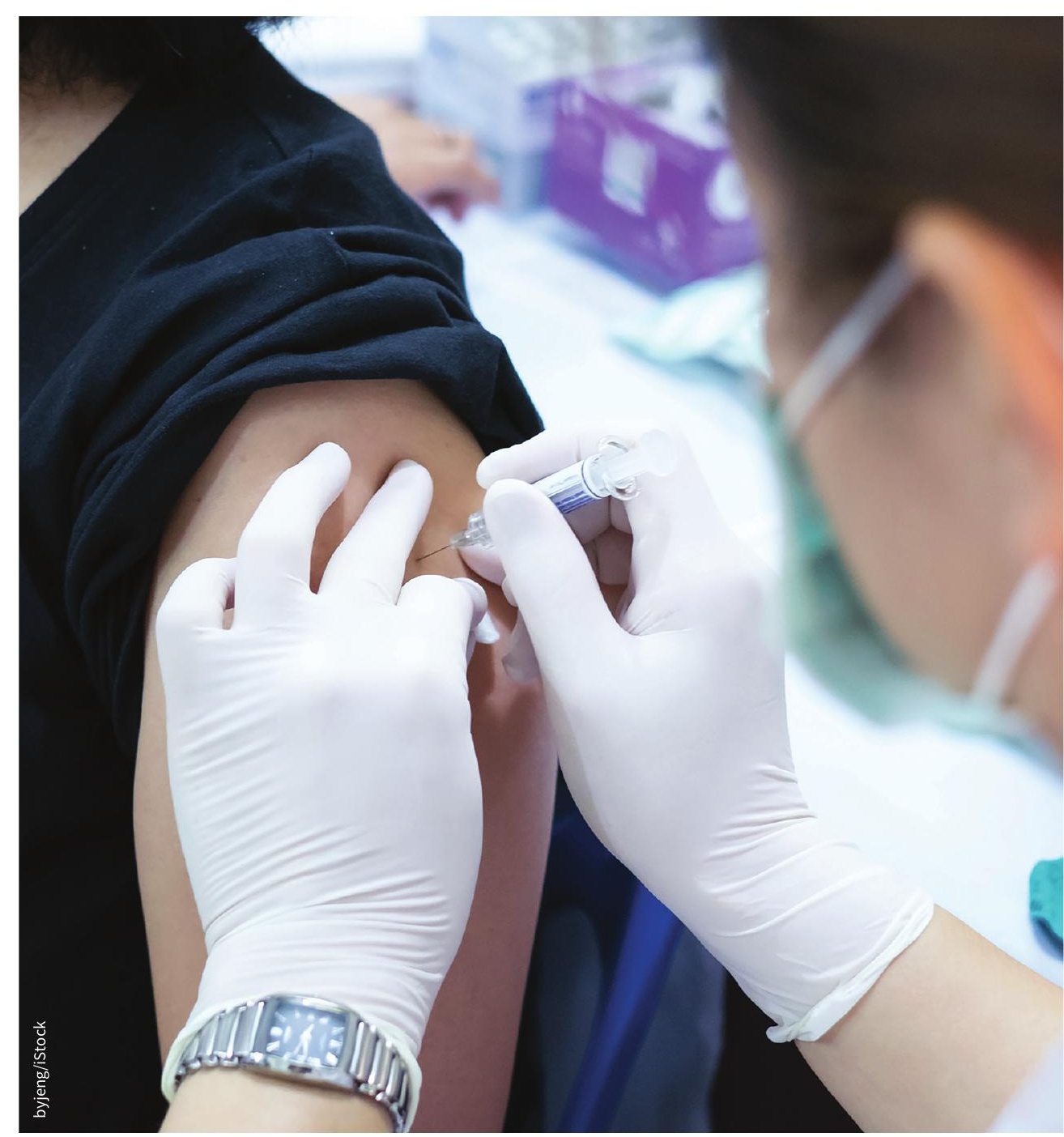

A new global influenza strategy emphasizes the importance of annual vaccinations, especially for health workers.
There has been progress since 2009 but gaps remain, particularly when it comes to electronic systems for tracking vaccine stock and uptake, according to Bonnie Henry, British Columbia's provincial health officer.

\section{Lauren Vogel, CMAJ}

